\title{
Making $\mathrm{HCl}$ Theory Work An Analysis of the Use of Activity Theory in $\mathrm{HCl}$ Research
}

Clemmensen, Torkil; Kaptelinin, Victor; Nardi, Bonnie

Document Version

Accepted author manuscript

Published in:

Behaviour and Information Technology

DOI:

10.1080/0144929X.2016.1175507

Publication date:

2016

License

Unspecified

Citation for published version (APA):

Clemmensen, T., Kaptelinin, V., \& Nardi, B. (2016). Making HCI Theory Work: An Analysis of the Use of Activity Theory in $\mathrm{HCl}$ Research. Behaviour and Information Technology, 35(8), 608-627.

https://doi.org/10.1080/0144929X.2016.1175507

Link to publication in CBS Research Portal

\section{General rights}

Copyright and moral rights for the publications made accessible in the public portal are retained by the authors and/or other copyright owners and it is a condition of accessing publications that users recognise and abide by the legal requirements associated with these rights.

Take down policy

If you believe that this document breaches copyright please contact us (research.lib@cbs.dk) providing details, and we will remove access to the work immediately and investigate your claim. 


\title{
Making HCl Theory Work: An Analysis of the Use of Activity Theory in HCl Research
}

\section{Torkil Clemmensen, Victor Kaptelinin, and Bonnie Nardi}

\author{
Journal article (Post print version)
}

Cite: Making HCI Theory Work : An Analysis of the Use of Activity Theory in HCI Research. / Clemmensen, Torkil; Kaptelinin, Victor; Nardi, Bonnie. In: Behaviour and Information Technology, Vol. 35, No. 8, 2016, p. 608-627.

This is an Accepted Manuscript of an article published by Taylor \& Francis in Behaviour and Information Technology on 04 May 2016, available online:

http://www.tandfonline.com/10.1080/0144929K.2016.1175507

Uploaded to Research@CBS: June २०16

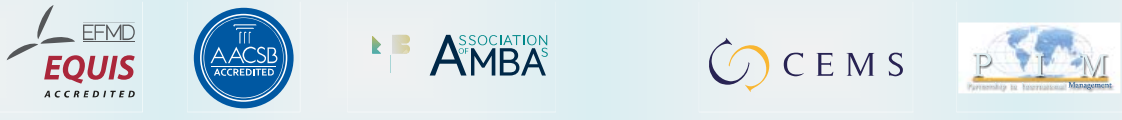




\title{
Making HCI Theory Work: An Analysis of the Use of Ac- tivity Theory in HCI Research
}

\author{
Torkil Clemmensen (corresponding author) ${ }^{1,}$ Bonnie Nardi ${ }^{2}$, \\ Victor Kaptelinin ${ }^{3}$
}

${ }^{1}$ Copenhagen Business School, Department of IT Management, Howitzvej 60, Frederiksberg, DK, tc.itm@cbs.dk; ${ }^{2} U C$ Irvine, School of Information \& Computer Sciences, Irvine, USA; ${ }^{3}$ Umeå University, Department of Informatics, Umeå, SE

\begin{abstract}
This paper reports a study of the use of activity theory in HCI research. We analyze activity theory in HCI since its first appearance about 25 years ago. Through an analysis and meta-synthesis of 109 selected HCI activity theory papers, we created a taxonomy of five different ways of using activity theory: 1) analyzing unique features, principles, and problematic aspects of the theory; 2) identifying domain-specific requirements for new theoretical tools; 3 ) developing new conceptual accounts of issues in the field of HCI; 4) guiding and supporting empirical analyses of HCI phenomena, and; 5) providing new design illustrations, claims, and guidelines. We conclude that HCI researchers are not only users of imported theory but also theory-makers who adapt and develop theory for different purposes.
\end{abstract}

Keywords: HCI theory; activity theory; theory use.

\section{Introduction}

One way to analyze the role and current status of theory in HCI is to examine how researchers have questioned, critiqued, used, and developed theory. This paper seeks to understand how HCI theory in general, and one theory in particular, activity theory, have been employed in HCI research.

Our premise is that the role of theory in HCI remains an open issue. On the one hand, theory is apparently central to HCI as a research field. The very emergence of HCI was, to a large extent, the result of the application 
of a particular theoretical approach, information processing psychology, to the analysis and design of interactive systems (Card, Moran, \& Newell, 1983; Clemmensen, 2006). Some of the most influential HCI works have been attempts to bring new theoretical insights to the field, (e.g., Bødker, 1991; Carroll, 1991; Dourish, 2001; Nardi, 1996; Winograd \& Flores, 1986). Recent years have brought conceptually oriented review papers that advocate clarifying what we know in subareas of HCI such as User Experience and Participatory Design (Bargas-Avila \& Hornbæk, 2011; Halskov \& Hansen, 2015).

However, these efforts have not ensured the development of a solid and widely accepted theoretical foundation for HCI. This situation is perhaps similar to that in the related field of Information Systems, which some see as unsuccessful in developing sustainable and widely used theory (Kjærgaard \& Vendel $\varnothing, 2015$ ). In HCI, the usefulness of the original information processing psychology perspective was questioned early in the history of the field (Carroll \& Campbell, 1986), and this perspective has never realized its promise of being a general theory of $\mathrm{HCI}$ (Clemmensen, 2006). A number of other approaches known as "secondwave theories" (Bødker, 2006; Kaptelinin et al., 2003) or "modern theories" (Rogers, 2012) such as the language-action perspective or distributed cognition, were introduced to HCI as alternatives to information processing psychology (Carroll, 2003; Monk \& Gilbert, 1995; Rogers, 2004; Winograd \& Flores, 1986). These theories have expanded the scope of HCI research, but each has its own challenges. First, the diversity of second-wave theories, which seem to partly overlap, raises questions regarding how to choose between them, or possibly how to combine them. Second, newer developments in HCI, especially the recent emphasis on experience, personal values, and designers' creative self-expression, present a problem for second-wave theories (Bødker, 2006), and suggest that HCI researchers should adopt an eclectic perspective not constrained by traditional distinctions between theory and practice, or laboratory experiments and field studies, see (Rogers, 2012). Examining these questions about how HCI researchers exploit the potential of a specific theory for supporting research and development is thus a timely issue.

To use theory to ask the big questions and produce new knowledge, HCI researchers need to know more about the sociocultural contexts of other researchers' use of theory, in the same way that designers need to know 
users' context of use in order to design systems and products for them. Knowing the sociocultural context of use of theory is not the same as understanding core topics for HCI, what kind of science $\mathrm{HCI}$ is, and how to study HCI. HCI does not have a set of core topics (Kostakos, 2015; Liu et al., 2014) or industrial constraints (Newman, 1994) that drives the field forward, leaving open the question of the purposes for which we produce theory. HCI theory appears in many new and creative forms, from engineering modelling techniques, solutions, and tools (Card, et al., 1983), to philosophically grounded discussions of categories of humantechnology relations (Fallman, 2011). But in which contexts are which forms of HCI theory more useful? Some argue that HCI should be studied in practice (Kuutti \& Bannon, 2014), but what are the researchers' reflection on the usefulness of the theory in their context?

In this paper, we present an in-depth study of the use of activity theory as one theory that has been used extensively in HCI. We examine the purposes of using activity theory, the forms of activity theory researchers have used, "classic" texts and concepts, and authors' reflections on the usefulness of the theory. We hope to give a sense of the empirical and theoretical landscape of activity theory in human-computer interaction, including what researchers have said about how it informed their practice.

\section{About activity theory in HCI}

This section provides a general outline of activity theory and a brief account of how it became a theoretical framework in HCI. The section does not intend to present a comprehensive exposition of the conceptual structure, historical developments, and current debates in activity theory. Detailed discussions of these issues can be found, for instance, in Leontiev (1978), Engeström (1987), Nardi (1996), Engeström et al. (1999), and Kaptelinin and Nardi (2006, 2012).

Activity theory, originally proposed by the Russian psychologist Alexey Leontiev (Leontyev) $(1978,1981)$ has its roots in the Russian psychology of the early $20^{\text {th }}$ century. Two main ideas, comprising the foundation of activity theory, the social nature of human mind, and unity and inseparability of human mind and activity, were formulated and elaborated by, respectively, Lev Vygotsky (1978) and Sergey Rubinshtein (1946), 
mostly in the 1920s and 1930s. Vygotsky's cultural-historical psychology (1978) considered culture and society as generative forces behind the very production of human mind, rather than external factors or conditions of its development. This general view was elaborated by Vygotsky into a number of more specific concepts, such as "the universal law of human development", according to which an individual's mental functions appear as distributed between the person and other people (i.e., as "inter-psychological") before they become appropriated by the individual (i.e., become "intra-psychological"). Rubinshtein (1946) argued that human mental processes (the internal) and human acting in the world (the external) are closely related and mutually determine one another.

Leontiev's activity theory builds on Vygotsky's cultural-historical psychology; it also adopts, and somewhat adapts, Rubinshtein's principle of unity and inseparability of human mind and activity. The foundational concept of Leontiev's theory is "activity", understood as a purposeful, social, mediated, multi-level, and developing interaction between actors ("subjects") and the objective world ("objects"). A central claim of the approach is that it is activity that places the subject in objective reality and transforms the reality into a form of subjectivity (Leontiev (1978). The human mind emerges, exists, and develops within the context of human activity as a whole, and therefore analysis of object-oriented activities should be considered a necessary prerequisite for understanding the human mind. An extensive program of theoretical and empirical research, conducted by Leontiev and his colleagues explored co-development of activity and mind at different levels of analysis: from biological and social evolution to child development to the development of perceptual and motor skills (Leontiev, 1978, 1981; Wertsch, 1981).

Activity theory emerged as an approach in Russian psychology, but eventually it transcended both geographical and disciplinary borders. In the last decades, especially since 1980s, Vygotsky's cultural historical psychology and activity theory (sometimes collectively labeled as "CHAT", that is, "cultural-historical activity theory") became increasingly known in the $\mathrm{West}^{1}$, in particular, owing to the work of Michael

${ }^{1}$ In this paper we do not account for what developments lead to activity theory being accepted in the West, and neither do we discuss 
Cole and James Wertsch (1986; see also Wertsch, 1981). In addition, activity theory became an interdisciplinary framework, employed not only in psychology but also in education, organizational learning, and human-computer interaction.

The extension of activity theory beyond geographical and disciplinary borders resulted in a major advancement of the theory itself. A wellknown and influential version of activity theory that extends the notion of activity to provide an account of collective activities and organizational practices, was proposed by Yrjö Engeström (1987, 1999). Engeström introduced the concept of the activity system model, which adds a third component, community, to Leontiev's "subject-object" interaction. The model also discusses different means mediating three-way interaction between "subject", "object", and "community": tools/ instruments, rules, and division of labor. The activity system, model, as well as representations comprising networks of activity system models, were extensively used in studies of various real-life practices work practices, in which special attention was paid to contradictions in (and between) activity systems as driving the development of practices (e.g., related to the adoption of new technologies).

Activity theory was introduced to HCI in the late 1980s-early 1990s, during a transition of the field from first-wave HCI, which was dominated by information processing psychology, to second-wave HCI which recognized the importance of human agency and motivation, and the social context of technology use. To the best of our knowledge, the first attempt to systematically apply activity theory in HCI was made by Susanne Bødker $(1989,1991)$, who employed the theory to argue that in the analysis and design of computing technology, it is critically important to take into account that people act through technology, rather than interact with it. More recently the theory has been used as a conceptual framework in a wide range of HCI studies, e.g., (Kaptelinin \& Nardi, 2006; Nardi, 1996) and has established itself as one of the most influential theories in

potential epistemological and ontological issues related to this process. A discussion of these issues can be found, for instance, in Wertsch (1981), Kozulin (1984), Cole and Wertsch (1986), Cole (1996), Kaptelinin and Nardi (2006). 
HCI (Rogers, 2012). As shown in the analysis in this paper, activity theory has been used in wide range of HCI studies, for various purposes and in various roles.

\section{Qualitative analysis and synthesis}

We conducted a qualitative analysis and meta-synthesis of the use of activity theory in a set of $109 \mathrm{HCI}$ activity theory papers dating from the first introduction of activity theory to HCI in late 1980s, e.g., Bødker (1989). In contrast to quantitative meta-analysis which first selects a set of papers and then applies a pre-defined analysis framework to do a statistical analysis, a qualitative meta-synthesis iteratively develops a template for analysis and synthesis of the content of the selected papers, given what is learned from reading the papers in each step, until it reaches a final version, which is then applied systematically on all papers (King, 2012; Stewart et al., 2012). The development of the evaluation

\section{- Step 1:}

Identify all publications that use the term 'activity theory' in Google Scholar (45600), Scopus (2524), WoS (1331), and ACM DL (868).

- Step 2:

Exclude publications that do not explicitly fulfill these criteria: English language, use the term "activity theory", published in an established, self-declared HCI outlet, and of academic nature with peer review.

Results: 416 publications in HCI outlets.

- Step 3:

Exclude posters, abstracts, editorials, commentaries, discussions, book reviews, short papers.

Results: 320 full journal/conference papers.

- Step 4:

Exclude papers that only cite or briefly mention activity theory.

Results: 109 papers, the final set of papers for meta-analysis and synthesis. 
criteria had four steps, beginning with a simple keyword approach to give a sense of the landscape of possible activity theory

Figure 1. Step-wise approach for identifying the set of papers and developing a evaluation criteria for analysis.

papers by using search engines and citation databases, and then in the later steps take the more realistic steps of focusing on top level journals and conferences in HCI and ending, and ending up with five themes for analysis, Figure 1.

\subsection{Step 1 -Searching for 'activity theory' across disciplines}

To identify HCI activity theory papers, we began with the simple idea that an activity theory HCI paper was any paper that used the term 'activity theory'. Not all relevant research outlets could be found in a single database. For example, at the time of our search, ACM DL did not include Computers in Human Behaviour, Interacting with Computers, and the INTERACT Conference. The results suggested varied numbers of potential activity theory papers: 45600 (Google Scholar), 2524 (Scopus), 1331 (WoS), and 868 (ACM DL) for 1989-2014.

\subsection{Step 2 -Searching for 'activity theory' in HCI outlets}

Having gained a feeling for the overall size of the search space across disciplines, we then excluded all publications that were not in English, not peer-reviewed scientific publications, and not explicitly HCI relevant. We excluded books and other types of publications that were not journals or conference proceedings. We did not exclude conferences, as these are primary outlets for research in computer science. Journal and conference outlets with a focus other than HCI were excluded, e.g., journal and conference proceedings such as Mind, Culture, and Activity Cognition, Technology and Work, Ergonomics, Scandinavian Journal of Information Systems, and conference proceedings from conferences in related fields such as Information Systems. We then did the search again, this time only in selected HCI outlets for the period from the beginning of the outlets publication and until and including 2014, see Table 1. At this point we had 416 papers. 


\subsection{Step 3-Regular full journal/ conference papers}

We then excluded panel descriptions, posters, introductions to special issues or invited discussion papers, extended abstracts, and short papers. A total of 96 papers was excluded in this step, Table 1. At this step we had 320 full papers.

Table 1. Search results for "activity theory" in selected HCI outlets (until 2014)

\begin{tabular}{|c|c|c|}
\hline Source title & $\begin{array}{l}\text { Publications us- } \\
\text { ing the term "ac- } \\
\text { tivity theory" }\end{array}$ & $\begin{array}{l}\text { Excluded in } \\
\text { step } 2 \text { (editori- } \\
\text { als, short pa- } \\
\text { pers, etc) }\end{array}$ \\
\hline CHI conference (1982-2014) & 89 & 48 \\
\hline CSCW journal (1992-2014) & 55 & 7 \\
\hline CSCW conference (1988-2014) & 44 & 7 \\
\hline Interacting with Computers (IwC) (1995-2014) & 42 & 10 \\
\hline $\begin{array}{l}\text { International Journal of Human Computer Studies } \\
\text { (IJHCS) (1994-2014) }\end{array}$ & 35 & 2 \\
\hline INTERACT conference (1984-2014) & 29 & 9 \\
\hline Computers in Human Behavior (CHB) (2001-2014) & 28 & 2 \\
\hline Human Computer Interaction (HCI) (1985-2014) & 27 & 1 \\
\hline $\begin{array}{l}\text { Behaviour \& Information Technology (BIT) (1996- } \\
\text { 2014) }\end{array}$ & 23 & 1 \\
\hline $\begin{array}{l}\text { International Journal of Human Computer Interaction } \\
\text { (IJHCI) (1989-2014) }\end{array}$ & 21 & 5 \\
\hline ACM TOCHI journal (1994-2014) & 20 & 3 \\
\hline AIS THCI journal (2009-2014) & 3 & 1 \\
\hline Total & 416 & 96 \\
\hline
\end{tabular}

Note: Search performed June 2015, in each outlet.

\subsection{Step 4-Substantial use of theory: forming the final set of papers for meta-analysis and synthesis}

We then selected the papers that had a "substantial use of activity theory" in the sense that they: cited at least one classic HCI activity theory text or a set of activity theory references, used activity theory to analyze a design, user activity, or concept (such as affordances), or reflected on the use of activity theory in HCI (see Table 2). After having gone through the 320 full papers, we excluded 211 papers that did not show substantial use of activity theory. 
Table 2. Evaluation criteria for an HCI paper with substantial use of activity theory

(1) A clear example of an activity theory paper, it tells the reader in the title, abstract and keyword that this is about activity theory, it cites the reference $\mathrm{HCI}$ activity theory texts, it uses theory deeply and in a substantial way, and it reflects core HCI activity theory concerns. For example, the paper can be summarized as "...the model below was developed, inspired by activity theory..."

(2) The paper is about activity theory, it does cite reference activity theory texts, and it uses theory in a reasonable way, although not too deep. For example, the paper draw on concepts taken from activity theory, such as "activity awareness" derived from Bødker, 1996; Bardram, 1998, or "activity-based" or "activity-centric" concepts.

(3) The paper is about activity theory per se, up to a point, and cites some, but not all relevant activity theory and activity theory texts. The use of activity theory may still be limited.

(4) The paper is not an activity theory paper per se, but it is about core concerns for activity theory, and it does cite activity theory literature. For example a paper analysing the concept of "context", or papers that discuss activity theory, even if this is not the main aim of the paper, is a paper with substantial use of activity theory.

papers falling below this line were excluded-

(5) The paper is not activity theory oriented in a deep way, but only cites some activity theory literature, and the paper is much more focused on some other, non-AT, concept. Though the paper may mention activity theory several times, it does not really use activity theory (e.g., the paper may cite Bødker, but does not say anything about activity theory).

(6) Not much on activity theory per se. The paper does not have much on HCI activity theory per se, that is, only use of activity theory is a reference in one sentence to an activity theory paper. For example, the term "activity" may be mentioned in the paper, but activity theory is not discussed, except for a single citation, such as "It has been long known that the context of use is an important factor in human-computer interaction (e.g. Suchman, 1987; Nardi, 1995)".

We then analyzed and synthesized a final set of 109 papers (Table 3 and the Appendix).

Table 3. 109 HCI papers that engage activity theory.

\begin{tabular}{|c|c|}
\hline \multicolumn{2}{|r|}{ Journals } \\
\hline HCI (10) & $\begin{array}{l}\text { Bødker, 1989; Bødker, 1996; Bødker, 1998; Benyon and Imaz, 1999; } \\
\text { Greenberg, 2001; Bødker and Andersen, 2005; Matthews, Rattenbury, and } \\
\text { Carter, 2007; Bødker and Klokmose, 2011; Kaptelinin and Bannon, 2012; } \\
\text { Jaferian et al., } 2014\end{array}$ \\
\hline BIT (8) & $\begin{array}{l}\text { Carroll, 1996; Arestova, Babanin, and Voiskounsky, 1999; Herrmann et al., } \\
\text { 2004; Convertino et al., 2007; Chauvin, Morel, and Tirilly, 2010; Ang, } \\
\text { Zaphiris, and Wilson, 2011; Lundvoll Nilsen, 2011; Korpelainen and Kira, } \\
2013\end{array}$ \\
\hline
\end{tabular}




\begin{tabular}{|c|c|}
\hline IJHCS (10) & $\begin{array}{l}\text { Erskine, Carter-Tod, and Burton, 1997; McCarthy et al., 1997; Decortis, } \\
\text { Noirfalise, and Saudelli, 2000; Macaulay, Benyon, and Crerar, 2000; } \\
\text { Wright, Dearden, and Fields, 2000; Carroll et al., 2003; Norros and } \\
\text { Nuutinen, 2005; Paulson, Cummings, and Hammond, 2011; Law and Sun, } \\
\text { 2012; Belkadi et al., } 2013\end{array}$ \\
\hline $\operatorname{IwC}(12)$ & $\begin{array}{l}\text { Gobbin, 1998; Turner and Turner, 2001; Decortis, Rizzo, and Saudelli, } \\
\text { 2003; Folcher, 2003; Pargman, 2003; Pargman and Wærn, 2003; Rabardel } \\
\text { and Bourmaud, 2003; Meira and Peres, 2004; Carroll et al., 2006; Barr, } \\
\text { Noble, and Biddle, 2007; Norros, Liinasuo, and Hutton, 2011; Sjölie, } 2012\end{array}$ \\
\hline CSCW (18) & $\begin{array}{l}\text { Engeström, 1999; Westerberg, 1999; Bardram, 2000; Barthelmess and An- } \\
\text { derson, 2002; Clases and Wehner, 2002; Collins, Shukla, and Redmiles, } \\
\text { 2002; Fjeld et al., 2002; Halverson, 2002; Korpela, Mursu, and Soriyan, } \\
\text { 2002; Miettinen and Hasu, 2002; Nardi, Whittaker, and Schwarz, 2002; } \\
\text { Spasser, 2002; Zager, 2002; Carmien et al., 2004; Schmidt and Wagner, } \\
\text { 2004; Lauche, 2005; Nardi, 2005; Bødker and Petersen, } 2007\end{array}$ \\
\hline IHCI (9) & $\begin{array}{l}\text { Honold, 2000; Bedny and Karwowski, 2003; Mühlfelder and Luczak, } \\
\text { 2003; Chaiklin, 2007; Bedny, Karwowski, and Sengupta, 2008; Mohame- } \\
\text { dally and Zaphiris, 2009; Bedny, Karwowski, and Bedny, 2010; Mahatody, } \\
\text { Sagar, and Kolski, 2010; Bedny, Karwowski, and Bedny, 2012 }\end{array}$ \\
\hline CHB (10) & $\begin{array}{l}\text { Owen, 2001; Raven, 2006; Roda and Thomas, 2006; Liaw, Huang, and } \\
\text { Chen, 2007; Young, 2008; Chan, 2009; Hannan, 2011; Zitter et al., 2009; } \\
\text { Dennen, 2014; Peña-Ayala, Sossa, and Méndez, 2014 }\end{array}$ \\
\hline TOCHI (6) & $\begin{array}{l}\text { Petersen, Madsen, and Kjær, 2002; Bardram, 2009; Benbunan-Fich, Adler, } \\
\text { and Mavlanova, 2011; Convertino et al., 2011; Oviatt et al, 2012; } \\
\text { Tomlinson et al., } 2013\end{array}$ \\
\hline THCI (1) & Luse et al., 2011 \\
\hline \multicolumn{2}{|r|}{ Conferences } \\
\hline CHI (10) & $\begin{array}{l}\text { Kuutti and Bannon, 1993; Kaptelinin, 2003; Voida and Mynatt, 2009; } \\
\text { Sambasivan et al., 2010; Baumer and Tomlinson, 2011; Yardi and } \\
\text { Bruckman, 2011; Kaptelinin and Nardi, 2012; Park and Chen, 2012; } \\
\text { Houben et al., 2013; Kuutti and Bannon, 2014 }\end{array}$ \\
\hline CSCW (10) & $\begin{array}{l}\text { Engestrom, Y., Engestrom, R., and Saarelma, 1988; Kuutti and Arvonen, } \\
\text { 1992; Bardram, 1998; Tuikka, 2002; Nardi, Schiano, and Gumbrecht, } \\
\text { 2004; Neale, Carroll, and Rosson, 2004; Bardram and Doryab, 2011; Döw- } \\
\text { eling, Schmidt, and Göb, 2012; Hautasaari, 2013; Quinones, } 2014\end{array}$ \\
\hline $\begin{array}{l}\text { INTERACT } \\
(5)\end{array}$ & $\begin{array}{l}\text { Nardi et al., 1993; Norris, Wong, and Rashid, 1999; Mwanza, 2001; } \\
\text { Bødker and Klokmose, 2013; Klokmose and Bertelsen, } 2013\end{array}$ \\
\hline
\end{tabular}

Note: See the Appendix for a complete list of references to the 109 papers.

At the same time as we narrowed down the set of papers, we developed our understanding of what to look for in an activity theory paper. In step four we ended up with five themes for analysis and synthesis. Our first and primary theme for the synthesis was the purpose of using activity theory, i.e., the context in which activity theory was used. The use of theory in HCI research is context-specific, and depends on who uses the theory and how and why. Identifying the main purposes of using activity theory was our way to take the papers' research contexts into account. The second theme was a paper's reference to classic activity theory texts, 
i.e., did the paper cite reference activity theory texts? In bibliometry, a classic text is one that has not become obsolete after decades of popularity (Walstrom \& Leonard, 2000). The Psychology of Human-Computer Interaction by Card, Moran and Newell (Card, et al., 1983) for example, is a classic HCI text. A classic text can be cited in many ways, e.g., for authority or for specific arguments, all of which may tell us something about how researchers appropriate classic activity theory knowledge in a paper.

The third theme was the specific activity theory concepts the paper used, i.e., which activity theoretical concepts such as mediation, internalization, and development did the paper use? This theme would provide insight as to whether a paper had used the theory as a gestalt, or used a few key concepts from the theory.

The fourth theme was whether the paper employed activity theory alone or in combination with other theories. What role did activity theory play and how was it integrated with other theories?

The fifth theme was the authors' comments and reflections on their uses of activity theory. What did the authors think worked and did not work in their papers? Insights from the use of theory in psychology (Greenwald, Pratkanis, Leippe, \& Baumgardner, 1986) have indicated that too fixed a view on theory may obstruct research. Thus we could learn in what sense researchers expected activity theory to be useful, and whether social, cultural, organizational, technical or political issues had been associated with the use of activity theory.

For the synthesis, all three authors analyzed the same set of 12 randomly selected papers, and discussed and adjusted the analysis. We then read and reread the 109 papers, systematically looking for relations between the 'purpose of using AT' and the other four categories in the final evaluation criteria.

\section{$4 \quad$ Findings}

In this section we discuss the variety of ways in which activity theory was used in the corpus of selected papers. The analysis is structured around the first of the five themes, identified in the previous section, i.e., the papers are divided into five groups according to the main purpose of using the theory. The remaining four themes are then used to analyze 
each of the five groups of papers, one at a time. The decision to adopt this structure was based on the assumption that the use of theory in HCI research is context-specific. The way a theory is cited, the specific concepts that are found relevant, the place of the theory in the paper, and the perceived strengths and weaknesses of a theory, all depend on the particular research context in which the theory is being employed for some meaningful purpose. Identifying the main purposes of using activity theory was a way for us to take the research contexts into account.

The five-group division was produced in three steps. First, we differentiated between papers predominantly employing the theory as (a) an $o b$ ject of analysis, that is, focusing on activity theory per se (e.g., making the case for the theory as an HCI framework or comparing it to other theories) or (b) a conceptual tool, that is, applying activity theory to support analysis and/or design. The former group has five papers, while the overwhelming majority belongs to the latter group. At the second step, the 104 papers in the conceptual tool group were divided into two subgroups depending on whether activity theory was used to support analysis (87 papers) or design (17 papers). Finally, conceptual tool papers were further divided into three sub-groups: (a) meta-tool, that is, activity theory as a theoretical influence for developing a new analytical tool proposed in the paper (16 papers), (b) tool for conceptual analysis, that is, activity theory used as an analytical tool in a predominantly conceptual analysis of human-computer interaction (30 papers), and (c) tool for empirical analysis, that is, activity theory used as an analytical tool in a 
predominantly empirical analysis of human-computer interaction (41 papers). Figure 2 schematically shows the divisions:



Figure 2. Dividing the corpus of selected HCI papers according to the main purpose of using activity theory. The five resulting groups are in bold typeface.

Assigning papers to certain groups was often a non-trivial task. Many papers used theory for several purposes, for instance, an empirical study followed by a discussion of implications for design. Grouping problems were addressed by discussions among the three authors; the final version of the group division is a result of a series of adjustments and modifications stemming from the discussions.

\subsection{Activity theory as an object of analysis}

In the five papers comprising this group, the main purpose of using the theory was to analyze and further develop activity theory. In these papers, Nardi (1996), Engeström (1987) and Bødker (1991) were used as early and authoritative source texts that present activity theory as a common vocabulary and rich framework for studying context in HCI.

The papers argued that activity theory provides a number of useful concepts that support the understanding of technology, including context, 
tool mediation, contradiction, object, and the hierarchical structure of activity. Bødker (1989), Halverson (2002), Decortis et al. (2003), and Baumer and Tomlinson (2011) discussed the concept of context as a defining feature of activity theory. The emphasis on context suggests that activity theory can be a conceptual framework to describe technology in a particular setting "... situated within the broader organizational context" Halverson (2002). Baumer and Tomlinson (2011) engaged with the activity theory concept of object in a comparison to distributed cognition. Decortis et al. (2000) discussed the similarities and differences between the notions of "goals" in distributed cognition and "object" in activity theory. Bedny and Karwowski (2003) noted that activity theory is useful for HCI because it "has precise units of analysis and carefully elaborated concepts and terminology". The concept of tool mediation was discussed by Decortis et al. (2000) and Halverson (2002). Halverson observed: "Naming a category 'mediating artifacts' focuses the analyst's attention around those objects used by the subjects of the activity system. Naming helps communicate to others - particularly when they do not understand the particular domain." Decortis et al. (2000) noted that, "Contradictions within the activity and with social forces are then seen as the origin of any change". Bedny and Karwowski (2003) studied inventory processes for a manufacturing firm and found the notion of hierarchy in activity theory useful: "[T]his process is organized into a hierarchy of recursive subsystems directed to achieve goals of various operations and actions...Hence, cognition should be studied as a continuous processing system and as a system of cognitive actions and operations".

Some authors mentioned difficulty learning activity theory concepts, and that comparative analysis with activity theory may be difficult due to the existence of multiple meanings of the key activity theory concepts. Baumer and Tomlinson (2011) remarked that activity theory may be difficult to learn in that there are multiple meanings of the concept of object (2011). At the same time, Halverson (2002) said that "Despite early calls that it was too difficult to learn [activity theory]...the range of practitioners here-academics, members of large and small companies, as well as researchers - attest to its growing converts". 


\subsection{Activity theory as a theoretical influence in the develop- ment of a new analytical tool}

In this group of 17 papers, activity theory was used for developing new analytical tools, either as a sole basis for developing a tool, or by combining it with other theory (or theories) to propose a new framework for analysis and evaluation, intended for a specific work or learning domain. For this purpose, tool mediation was an important concept. The ways activity theory can be applied appear to depend on multiple issues: the type of domain, whether it is used by a whole community or an individual researcher, what variant of the theory is used, and with which ontological perspective it is applied. Nardi (1996), Engestrøm (1987) and Bødker (1991) were cited as introductions to activity theory's history, key concepts, and how to apply the theory. The concept of tool mediation was the most important concept in this group of papers. Ang et al. (2011) devised a tool to guide the design of computer-based artifacts as support for constructionist learning systems. Belkadi et al. (2013) used activity theory to build a generic situation model of awareness in collaborative design. Bardram and Doryab (2011) built a tool to analyze qualitative data pertinent to activity in hospitals. Benbunan-Fich et al. (2011) created a tool to validate a set of metrics for multitasking. Bødker and Klokmose (2011) developed a "human-artifact model" derived from activity theory to analyze ecologies of different kinds of artifacts used together in activities. Norros et al. (2011) created a tool for communities to design technologies for local activities. Bedny et al. $(2010,2012)$ devised tools for reliability assessment and task complexity analysis.

The concept of context was engaged to describe specific domains (Bardram, 1998; Rabardel and Bourmaud, 2003; Spasser, 2002; Young, 2008; Jaferian et al., 2014). Kuutti and Bannon (1993) used the concept of the hierarchy of activity to develop a model of the process of enlarging the domain of HCI research.

When reflecting on their use of activity theory, authors noted certain benefits but also problems to wrestle with. Mühlfelder and Luczak described problems analyzing dynamics over time (2003). Ang et al. discussed difficulties modelling interactions between activity systems (2011). They argued that activity theory emphasizes cognitive aspects of human activity, and may sometimes overlook organizational aspects as Engeström 
(1999) discussed. For certain types of human-human interaction analyses, some authors argued that activity theory needs to be supplemented with other theories to make it possible to develop more specific tools. For example, Meira and Peres needed specific linguistic tools for their analysis (2004). Due to an elaborate theoretical vocabulary, activity theory may lead to analytical tools that are cumbersome or time consuming to use (Bardram and Doryab, 2011), which may also be the case for the new analytical tools derived from activity theory (Belkadi et al., 2013). In sum, the main advantage of activity theory identified in this group of papers was that activity theory works with different ontological perspectives and helps avoid reductionism. Because it has a rich theoretical vocabulary and is open and expandable, activity theory can be used for analysis of a variety of human work domains, by both whole research communities and individual researchers. However, the papers also mentioned that activity theory has some shortcomings when analyzing dynamics over time and interaction between activity systems, and it may overemphasize analysis of cognition.

\subsection{Activity theory as a theoretical frame for conceptual analyses}

In this group of 30 papers, researchers applied activity theory to conceptualize various kinds of computer supported work and communication activities, with a focus on interfaces and development of IT systems. Classic texts were cited as explanations of different philosophical and psychological approaches to HCI, e.g., as an alternative to the information processing model (Barr, Noble, \& Biddle, 2007); for activity theory's philosophical foundations (Benyon \& Imaz, 1999), and as a specific instance of a general sociocultural approach (Kaptelinin \& Nardi, 2012). Classic texts were also cited for defining key activity theory concepts, for example, defining levels of activity (Bødker \& Andersen, 2005) or Engeström's approach to extending the concept of conflict (Bødker, 1996). An early paper by Kuuti and Arvonen (1992) cited Engeström (1987) for presenting a structural model of "...a "fundamental type" of context, which is called activity".

Nearly all of the 30 papers used the concept of object to establish the objectives of activities and to identify specific things transformed in activity. Chaiklin (2007), for example, established the object of his inquiry 
as obligatory mass schooling for all children to satisfy a societal need. Bødker and Andersen (2005) identified concrete objects in activities, e.g., carpenters hit "nail objects," ship officers move "engine control objects" from work station to work station at the ship's bridge, and maritime pilots identify "foreign ships objects". Barr et al. (2007) noted that video games researchers study how "avatar objects" are transformed in game activities. Hannan (2011) observed that software development use cases can be "business objects". Arestova et al. (1999) talked about computer-mediated communication as "new external tools (both sign systems and material objects)". Kuutti and Bannon (2014) talked about the "object of [HCI] research".

Some researchers studied the concept of object itself, such as proposing pseudo-collective objects (Zager, 2002), and discussing definitions of the concept of object (Greenberg, 2001). Other concepts included the hierarchy of activity, mediation, contradiction, and development. For example, the concept of development was used to conceptualize historical development in mediators and the division of labor in Bødker and Andersen (2005) and Sjölie (2012), and for personal development in Carroll et al. (2006). Affordance was given an activity theory interpretation in Kaptelinin and Nardi (2012), who analysed affordances as instrumental within activity. Other authors noted that key activity theory concepts, such as mediators and objects, could be further conceptually developed, e.g., into "co-occurring mediators" and "immediate and ultimate objects" (Bødker and Andersen, 2005). Processes of development can be extended to concepts such as "instrumental genesis" that transform artifacts (Rabardel \& Bourmaud, 2003). Mohamedally and Zaphiris used the concept of mediation to capture processes in diagramming design activities (2009).

Authors remarked that it is possible to integrate activity theory with other theories in a more comprehensive framework to analyze new situations. Some authors felt that activity theory by itself was not sufficient to conceptualize what goes on in work settings (Hannan, 2011). Kaptelinin and Bannon (2012) argued that activity theory needs to be further developed to deal with sets of interrelated activities that use shared pools of resources. Korpela et al. (2002) commented that activity theory by itself was not enough for the development of standard sets of data to compare across countries. 


\subsection{Activity theory as a conceptual tool for empirical anal- yses}

In this group of 41 papers, HCI researchers used activity theory as a theoretical framework for empirical analysis to formulate specific questions for their studies. The papers focused on activity in diverse contexts including:

- healthcare (Engestrom, Y., Engestrom, R. \& Saarelma, 1988; Nardi et al., 1993; Bardram 1998; 2000; Lundvoll Nilsen, 2011; Nardi et al., 1993; Park and Chen, 2012) and elder care (Westerberg, 1999),

- education (Carroll et al., 2003; Law and Sun, 2012; Liaw et al., 2007; Pargman, 2003; Pargman and Wærn, 2003; Raven, 2006; Turner and Turner, 2001),

- corporate and industrial work (Barthelmess and Anderson, 2002; Bødker and Petersen, 2007; Chauvin et al., 2010; Collins et al., 2002; Folcher, 2003; Lauche, 2005; Wright et al., 2000; Miettinen and Hasu, 2002; Nardi et al., 2002; Norros and Nuutinen, 2005; Owen, 2001; Schmidt and Wagner, 2004),

- office work (Voida and Mynatt, 2009),

- household product usage (Honold, 2000; Petersen et al., 2002),

- social media use (Nardi et al., 2004; Yardi and Bruckman, 2011; Dennen, 2014; Hautasaari, 2013),

- technology use in urban slums (Sambasivan et al., 2010)

- technology use in controlled experimental settings (Norris et al., 1999; Bedny et al., 2008; Chan, 2009; Paulson et al., 2001; Oviatt et al., 2012).

The papers in this group cited the classic texts as a general theoretical framework for empirical analysis. The classics were often cited together as a cluster that formed a uniform theoretical gestalt or a concrete analytical framework to interpret empirical evidence. For example, Korpelainen and Kira (2013) cited Engestrøm (1987) and Nardi (1996) for presenting general activity theory.

The activity theory concepts most widely used in the papers were tool mediation to help understand artifacts; context to discuss meaningful human activity; and contradictions, tensions, and breakdowns, to help understand the development of activity systems. Thirteen papers had a strong focus on tool mediation. For example, Bødker and Petersen (2007) 
studied a configuration of artifacts used in media production. Pargman and Waern (2008) studied collaborative writing tools. Bardram (1998) studied surgical tools. Oviatt et al. (2012) studied user interfaces for higher learning activities. Twelve papers focused on context. For example, Barthelmess and Anderson (2002) produced a rich contextual description of software development as a collaborative activity. Owen (2001) analyzed the organizational context of workplace learning. Nine papers used the concept of contradiction, as well as the closely related notion of breakdown. For example, Miettinen and Hasu (2002) analyzed contradictions in a network of activity systems related to innovation. Law and Sun (2012) examined breakdowns in a set of video games. Hautasaari (2013) used the concept of hierarchy to analyse and design support for Wikipedia article translation.

In reflecting on their applications of activity theory, many authors commented that the breadth of activity theory helped position their research within a wider purview. Owen (2001) noted that, "The strength of activity theory is that it draws attention to history and change, and the influence of contradictory structures in mediating everyday work activity". Bardram (2000) said, "Activity Theory informs - in the original sense of the word as giving form or character to- the task of analyzing cooperative work settings and devising mediating artifacts". Korpelainen and Kira (2013) pointed out that the "strength of the activity system model lies in its being systemic and holistic", but also pointed out that it could be "challenging to categorize the problems that were identified unequivocally into the categories between different elements". In general, the reflections suggested that activity theory offers a rich framework that covers a wide range of HCI-relevant issues and factors including historical, social and organizational context. It was noted that empirical analyses informed by activity theory do not deliver specific predictions about the nature of work and its computer support.

\subsection{Activity theory as a framework for design}

In this group of 17 papers, HCI researchers used activity theory to support design reflexivity, provide a general structure for analysis and design explorations, and develop a better understanding of the role of technological artifacts in everyday contexts. 
Six papers reported the design of concrete systems: a table-top based groupware system (Fjeld et al., 2002), an interactive learning environment supporting children's narrative activities (Decortis et al., 2003), a desktop system for knowledge workers (Houben at al., 2014), a personal project management system (Kaptelinin, 2003), and a hospital system for communication and information (Bardram, 2009). The last two systems implemented different versions of the activity-centric computing framework.

Six papers dealt with design methodology. Several approaches to structuring and guiding the design process, informed by activity theory, were proposed: a methodology for designing corporate network security visualizations (Luse et al., 2011), a conceptual model for the design of interactive systems (Döweling et al., 2012), guidelines for designing electronic whiteboards (Klokmose and Bertelsen, 2013), a computer system design methodology based on Engeström's activity system model (Mwanza, 2001), a framework for analysis, design, and evaluation of peripheral displays (Matthews et al., 2007), a methodology for modelling the development of groupware (Herrmann et al., 2004), and dialogical techniques for the design of websites (Erskine et al., 1997).

The remaining five papers addressed a variety of other topics, such as the relationship between ethnography and theory in design (Macauley et al., 2000); designing sociotechnical support for people with cognitive disabilities (Carmien et al., 2004); conceptualizing notions of task (Zitter et al., 2009) and anticipation (Peña-Ayala et al., 2014), both intended to support the design of learning environments; and common ground and awareness in emergency management planning (Convertino et al., 2011).

The papers cited activity theory classics as providing guidance for design activities. For example, Houben et al. (2014) cited a classic text as their theoretical basis: "...we ground our design in Activity Theory (AT) (Engeström 1987)", and "to make activity theory more concrete in context of the three problems of the contemporary desktop interface, we present three guidelines...".

Activity theory concepts used were context to inform design and describe use situations, tool mediation to understand the role of technology in changes in work practices, and object to define the task to be supported by the design. For example, Mathews et al. said, "Activity Theory provides a framework for describing user context... and consequently...a 
framework for describing how people and peripheral displays interact in various situations" (2007). Klokmose and Bertelsen (2013) analyzed how information on a whiteboard was remediated to and from the whiteboard, and how designing artificial limitations on an electronic whiteboard could help maintain a key quality of a whiteboard - that when content is erased, it is gone. Peña-Ayala et al. (2014) defined objects in the learning environment and how they were taken into account to support educational activities.

When activity theory was the central theory it was used to provide general insights into the nature of design. New conceptual tools were illustrated with concrete designs and details of implementation, and presentations of new systems were framed in activity theory discussions from which general claims were made. Klokmose and Bertelsen (2013), for example, conceptualised the use of whiteboards with concepts derived from activity theory, and suggested how new designs could be based on the analysis. When activity theory played a secondary role, it was used to supplement insights from other frameworks, or used for comparison with the main design framework.

Some authors noted that activity theory helped them maintain critical distance so they could analyze their settings more productively. Macauley et al. (2000) said, "The explicit use of theoretical frameworks, at least those such as [activity theory] which are particularly suited to design issues, discourages the tendency for ethnographers to see themselves as 'proxy users' by encouraging greater reflexivity about the researcher's role in constructing the object of study". The main advantages of activity theory mentioned in the design papers were: providing a structure for analysis and design explorations, understanding the role of artifacts in everyday contexts, and supporting reflexivity.

The papers mentioned certain limitations of activity theory. Mathews et al. (2007) observed that activity theory did not obviate the need for time consuming design processes: "The major limitation of our Activity Theory framework is that it does not alleviate the difficulties of applying design and evaluation methods. It guides the design and evaluation processes, but design and evaluation methods remain challenging and timeconsuming to employ". As in other uses of activity theory, many authors found it advantageous to complement activity theory with other approaches. Luse et al. (2011) observed: "[A] marriage between concepts 
and techniques used by activity theorists and researchers applying design science would...be fruitful".

\subsection{Activity theory in use with other theories}

In many cases, authors used activity theory in conjunction with other theories. This finding is perhaps not surprising given that activity theory is a broad conceptual approach centered on concepts generically descriptive of human activity. Other theories were deployed for precision in specific domains or topical areas. For example, Spasser used activity theory with a realist ontology to develop an evaluation framework for digital library use (2002). Mühlfelder and Luczak used activity theory and conceptualizations of mental models to develop a new method for evaluating groupware (2003). Meira and Peres paired activity theory with conversation analysis to evaluate educational software (2004). Convertino et al. combined activity theory with a theory of small groups in a study of intergenerational groups (2007). Young used activity theory, cognitive load theory, and flow experience theory to develop an integrated framework for internet-mediated experiences for children (2008). Norros et al. used activity theory and cognitive ergonomics requirements engineering in a simulation of first responder services (2011). Barr et al. (2007) used activity theory with value theory and semiotics to analyze emotions in videogames. Kuutti and Bannon clustered activity theory with other social theories to discuss a turn to practice studies in HCI (2014). Tomlinson et al. (2013) applied activity theory in the development of a theory for collapse informatics, in particular to extend the notion of time to take into account the future. Activity theory has been combined with a wide range of other approaches including philosophical theories, social psychology, cognitive psychology, ethnomethodology, and systems development theory to create new analytical tools in varied domains.

Some papers used activity theory in a limited way to buttress other approaches. Quinones (2014) used activity theory to develop a coding scheme for analysing interviews. Carroll et al. (2003) used the concept of activity in formulating their own concept of "activity awareness." Chan (2009) employed Engeström's notion of activity system to formulate specific questions to be addressed in a study of decision support systems. In some papers activity theory was referred to briefly in making general claims about its usefulness, conceptual validity, or relevance. For instance, Wright et al. (2000) suggested using activity theory to explore 
function allocation in human-computer systems, and both Pargman (2003) and Chauvin et al. (2010) noted that there are similarities between the approach they employ, instrumental genesis, and activity theory.

All of that said, most papers used activity theory as the sole theory to conceptualize the research.

\subsection{Summary}

Our qualitative analysis of the use of activity theory in a carefully derived set of HCI activity theory papers indicated that HCI researchers used activity theory for five different purposes. When synthesizing and summarizing these findings, we found five different roles for HCI researchers making activity theory work:

(1) Meta-theoreticians considered activity theory itself as an object of analysis. They identified unique features and principles, as well as problematic aspects, of the theory and compared it to other "contextual" theories in HCI and related areas. For instance, Halvorson (2002) presented a systematic comparative analysis of activity theory and Hutchins' distributed cognition theory as conceptual frameworks for CSCW research.

(2) Theory-tool-makers used activity theory as a theoretical influence in the development of a new analytical tool. They identified needs and requirements for new theoretical tools and employed activity theory, sometimes in combination with other theories, to inform and guide the development of such tools. An example is Young (2008) which used activity theory in combination with cognitive load theory and flow experience theory to develop an integrated framework for analyzing internet-mediated experiences of children.

(3) Construct-developers employed activity theory as a tool for conceptual analysis and development. They applied the theory to address central issues and challenges in HCI, often in response to the emergence of new technologies. By doing so they also developed new sub-concepts of existing concepts, or expanded the application scope of existing concepts. An example is the paper by Bødker and Andersen (2005) that conceptualizes the historical development of mediators.

(4) Data interpreters used activity theory as a tool for empirical analysis. They used key theoretical constructs of the theory to identify and 
categorize specific empirical phenomena. For example, Bardram $(1998,2000)$ analyzed health care cooperative work settings and devised new artifacts.

(5) Design-oriented researchers used activity theory as a framework for design. The theory guided the iterative design process, or helped develop claims about the nature of the design process. These researchers provided new design illustrations, claims, and guidelines. An example is Mwanza (2001) which offered a design methodology based on Engeström's activity system model.

Table 4 summarizes the findings in the previous sections. 
Table 4. The five purposes of using activity theory (AT) and related thematic findings.

\begin{tabular}{|c|c|c|c|c|}
\hline Purpose & $\begin{array}{l}\text { Use of activity theory classic } \\
\text { texts }\end{array}$ & $\begin{array}{l}\text { Engagement with key activity theory } \\
\text { concepts }\end{array}$ & The role of activity theory in a HCI paper & Reflections on the use of activity theory \\
\hline $\begin{array}{l}\text { Object of } \\
\text { analysis }\end{array}$ & $\begin{array}{l}\text { Classic texts are cited as early } \\
\text { and authoritative, but difficult, } \\
\text { source texts. }\end{array}$ & $\begin{array}{l}\text { The concept of context is the most im- } \\
\text { portant AT concept }\end{array}$ & $\begin{array}{l}\text { AT can be the primary object for analysis, or one } \\
\text { theory among other theories in a comparative } \\
\text { analysis. }\end{array}$ & $\begin{array}{l}\text { AT has some unique features, and it has principles and is pre- } \\
\text { cise, and hence possible to analyze per se. Comparative anal- } \\
\text { ysis with AT may be difficult due to semantic problems with } \\
\text { key concepts. }\end{array}$ \\
\hline Meta-tool & $\begin{array}{l}\text { Classic texts are cited as intro- } \\
\text { ductions to AT's history, key } \\
\text { concepts and how to apply it. }\end{array}$ & $\begin{array}{l}\text { The concept of tool mediation is im- } \\
\text { portant. AT concepts are used as either } \\
\text { empirical, theoretical, or explanatory con- } \\
\text { cepts. AT concepts may also be inter- } \\
\text { preted with various domain specific as- } \\
\text { sumptions. }\end{array}$ & $\begin{array}{l}\text { One approach is to focus on the AT framework } \\
\text { and on basis of this develop a new analytical tool. } \\
\text { Another approach is to mix AT with other theory } \\
\text { in a new framework for analysis and evaluation } \\
\text { for a specific work or learning domain. }\end{array}$ & $\begin{array}{l}\text { AT works with different ontological perspectives, it helps } \\
\text { avoiding reductionism, and it has a rich theoretical vocabu- } \\
\text { lary, good means for visualizations, and it is open and expand- } \\
\text { able. Can be used for analysis of a variety of human work do- } \\
\text { mains, and by both whole user communities and individual re- } \\
\text { searchers. However, AT has shortcomings when analyzing dy- } \\
\text { namics over time and interaction between activity systems, } \\
\text { and it tends to focus on analysis of cognition. }\end{array}$ \\
\hline $\begin{array}{l}\text { Conceptual } \\
\text { analysis }\end{array}$ & $\begin{array}{l}\text { Classic texts are cited for } \\
\text { providing explanations of dif- } \\
\text { ferent philosophical and psy- } \\
\text { chological approaches to HCI, } \\
\text { and for defining selected con- } \\
\text { cepts. }\end{array}$ & $\begin{array}{l}\text { The concepts of object and transformation } \\
\text { are most important. AT concepts can } \\
\text { themselves be topics for further conceptu- } \\
\text { alization, and/or AT concepts can used to } \\
\text { conceptualize activity and describe its } \\
\text { specific characteristics. }\end{array}$ & $\begin{array}{l}\text { AT or a mix of AT and various other theory can } \\
\text { be applied to conceptualize various computer sup- } \\
\text { ported work and communication activities, with a } \\
\text { focus on interfaces and development of IT sys- } \\
\text { tems. }\end{array}$ & $\begin{array}{l}\text { AT works well to conceptualize real-world situations for } \\
\text { comparison across a variety of national and organizational } \\
\text { settings. AT concepts can be further developed, and non-AT } \\
\text { concepts can be re-interpreted as AT concepts. However, AT } \\
\text { should be more specific and flexible to be really useful for } \\
\text { generalization. }\end{array}$ \\
\hline $\begin{array}{l}\text { Empirical } \\
\text { analysis }\end{array}$ & $\begin{array}{l}\text { Classic texts are cited for } \\
\text { providing a general theoretical } \\
\text { framework for empirical anal- } \\
\text { ysis. }\end{array}$ & $\begin{array}{l}\text { The most important concepts are tool me- } \\
\text { diation, which helps understanding the ar- } \\
\text { tifacts; context, which helps take into ac- } \\
\text { count meaningful human activity; and } \\
\text { contradictions, tensions, and breakdowns, } \\
\text { which help understand the development } \\
\text { of activity systems. }\end{array}$ & $\begin{array}{l}\text { AT used alone directs empirical analysis by help- } \\
\text { ing to formulate specific questions for the study. } \\
\text { In a secondary role, selected AT concepts may in- } \\
\text { form parts the analyses, or support claims for con- } \\
\text { ceptual validity. }\end{array}$ & $\begin{array}{l}\text { AT offers a rich framework that covers a wide range of HCI- } \\
\text { relevant issues and factors including historical, social and or- } \\
\text { ganizational context. However, empirical analysis with AT } \\
\text { does not deliver predications about the nature of work and } \\
\text { computer support. }\end{array}$ \\
\hline Design & $\begin{array}{l}\text { Classic texts are cited for sup- } \\
\text { porting design activities. }\end{array}$ & $\begin{array}{l}\text { The most important concepts used are } \\
\text { context to inform design and describe use } \\
\text { situations, tool mediation to understand } \\
\text { the role of technology in changes in work } \\
\text { practices, and object to define the task to } \\
\text { be supported by the design. }\end{array}$ & $\begin{array}{l}\text { AT provides general insights into the nature of } \\
\text { design. New conceptual tools may be illustrated } \\
\text { with concrete designs and details of implementa- } \\
\text { tion, and presentations of new systems may be } \\
\text { framed in AT discussions from which general } \\
\text { claims can be made. When AT plays a secondary } \\
\text { role, it may be used to supplement insights from } \\
\text { other, more central frameworks, or used for com- } \\
\text { parison with the main design framework used. }\end{array}$ & $\begin{array}{l}\text { AT supports design reflexivity, providing a general structure } \\
\text { for analysis and design explorations, and supporting a better } \\
\text { understanding of the role of technological artifacts in every- } \\
\text { day contexts. However, using activity theory it is hard to give } \\
\text { concrete design examples, and practical guidance for design } \\
\text { is missing. }\end{array}$ \\
\hline
\end{tabular}




\section{$5 \quad$ Discussion}

\subsection{The roles of theory in $\mathrm{HCI}$}

By focusing on activity theory, and conducting an analysis and metasynthesis of 109 selected HCI activity theory papers, we created an empirically based taxonomy of five purposes of using activity theory, and used this to identify five roles for HCI researchers making HCI theory work.

Rogers (2012), in an overview of HCI theory, found that activity theory has been very popular in HCI as an explanatory framework that can "be mapped onto features of complex, real-world contexts". While our analysis of a set of activity theory HCI papers confirms the use of activity theory for empirical analysis of real world contexts, our findings further identified four other uses of activity theory in HCI, as we have discussed. In addition, a number of broader issues of theory in HCI, regarding its relevance and patterns of use, emerged in our analyses and are discussed below.

\subsection{Theory use vs. theory making}

Should HCI researchers be considered theory makers or theory users? Kjærgaard and Vendelø (2015) found that Information Systems (IS) researchers studying sensemaking theory often used this theory without explaining it or providing substantial theoretical background or discussion. They concluded that IS research is mainly concerned with empirical phenomena, pays little attention to theory construction and development, and that therefore IS is less likely to gain recognition as a reference discipline for other disciplines.

In contrast, there are reasons to believe that HCI is in a good situation when it comes to providing theoretical influence on other disciplines. There are indications that HCI acts as a reference discipline; for example, the classic activity theory HCI text Context and Conscioussness (Nardi 1996), has been widely cited outside HCI. Instead of theory use as passive consumption of a theory "product," we found numerous cases of theory development. These papers would for example tell the 
reader in the title, abstract and keyword that this is about activity theory, cite the reference HCI activity theory texts, use activity theory deeply and in a substantial way, and reflect core HCI activity theory concerns. We believe that HCI researchers can be described as not just "theory users" but also as "theory-makers".

However, not all HCI researchers are (or should be) either theory makers or theory users. Many HCI papers may better be characterized as experience reports (Newman, 1994) or merely challenging and provocative (Blackwell, 2015), with little or no trace of theory. We found more than 200 full papers (outside of the 109 in our corpus) that mentioned activity theory, but did not report any substantial theory use or theorymaking.

\subsection{Practical relevance of HCI theory}

The results of our qualitative meta-synthesis suggest that HCI has not fallen prey to Kuutti's (2010) concern that HCI research focuses only on practical usefulness to the exclusion of explanatory analysis. We found that the use of activity theory in design resulted in the development of concepts intended to be used by industry. We found that the papers we analyzed were concerned about topics of practical interest in varied domains of work, play, and learning. There are indications that historically, explicit use of theory in industry by HCI professionals tends to happen mostly in $\mathrm{R} \& \mathrm{D}$ contexts, or in consultancy work (Clemmensen, 2003). However, even the broad concept of usability, which hardly qualifies as theory, has been shown to be difficult to legitimize in industry and large organizations without first overcoming considerable organizational obstacles (Cajander, Janols, \& Eriksson, 2014). One possibility is that there is a misfit between the kind of HCI theory potentially useful for the global IT companies who can afford to have strong R\&D usability communities and who are top sponsors and contributors to HCI research (Bartneck \& Hu, 2009), and the needs of other companies for more organizationally adapted and commercially oriented HCI theory. We believe that our proposed taxonomy can help HCI researchers become more aware of the purposes for which a theory is applied, and the outcomes of theory-making and use that can be expected. 


\subsection{Various interpretations of theory in HCI research}

Our analysis shows that the meaning of theory itself varies from paper to paper; it is not fixed and immutable. In this respect our study goes against the view that a given theory always has a particular form (Gregor, 2006; Newman, 1994). The diversity of interpretations of theory in different contexts is determined by a number of factors.

First, we found several forms of activity theory being used, ranging from theory as a gestalt or framework for understanding context, to specific emphases on a few key concepts from activity theory such as mediation. Second, depending on the purpose of using activity theory, different concepts and principles were used. For instance, as shown in Table 5, the notion of context was the most widely used by in metatheoretical analyses, while in theory tool-making the most widely used was the notion of tool mediation.

Table 4. Papers with key activity theory concepts, across different roles of HCI theory

\begin{tabular}{|c|c|c|c|c|c|c|}
\hline & $\begin{array}{l}\text { Meta-the- } \\
\text { orist }\end{array}$ & $\begin{array}{l}\text { Theory } \\
\text { Tool- } \\
\text { maker }\end{array}$ & $\begin{array}{l}\text { Construct- } \\
\text { developer }\end{array}$ & $\begin{array}{l}\text { Empirical } \\
\text { analyst }\end{array}$ & $\begin{array}{l}\text { Design } \\
\text { theorist }\end{array}$ & Total \\
\hline & No $\%$ & No $\%$ & No $\%$ & No $\%$ & No $\%$ & No $\%$ \\
\hline Context & 480 & 638 & 1137 & 1844 & 1059 & 4945 \\
\hline Tool mediation & 240 & 744 & 1137 & 1434 & 635 & 4037 \\
\hline Object-oriented & 240 & 425 & 1343 & 717 & 529 & 3128 \\
\hline Contradictions & 240 & 319 & 620 & 1024 & 318 & 2422 \\
\hline Hierarchy & 240 & 425 & 517 & 410 & 318 & 1817 \\
\hline Transformation & 240 & 425 & 517 & 410 & 318 & 1817 \\
\hline Functional organ & 120 & 213 & 13 & 512 & $\begin{array}{ll}0 & 0\end{array}$ & 98 \\
\hline Other & 120 & 425 & 620 & 1229 & 318 & 2624 \\
\hline $\begin{array}{l}\text { Total number of } \\
\text { papers }\end{array}$ & 5100 & 17100 & 28100 & 41100 & 17100 & 108100 \\
\hline
\end{tabular}

Third, we found that activity theory was used in combination with other theories for different purposes and in different ways, such as comparing, adapting it to new work domains or to new technologies, or formulating design guidelines. Fourth, classic HCI theory texts were cited in many different ways, namely, as authoritative theory texts, introductions to the theory, or source of definitions, frameworks for empirical analysis, or loose guidelines. This variation in the use of activity theory 
suggests that it is extremely flexible, avoids the dogmatism associated with some theoretical work, and is always growing and changing. Indeed activity theory itself always says that it will grow and change as all human artifacts do (Kaptelinin and Nardi 2006)

\subsection{Sociocultural implications of using HCI theory}

One obvious feature of activity theory is that it explicitly covers historical, social, and organizational contexts to support a better understanding of the role of technological artifacts in these contexts. Authors suggested that activity theory should be developed more fully to account for analyzing dynamics over time, interaction between activity systems, and even more deeply engage social and organizational aspects.

As HCI develops broader, problem-based approaches such as sustainable HCI, ICT for development (ICTD), crisis informatics, and collapse informatics, the need to engage analyses of political economy and global dynamics suggests that activity theory must itself continue to develop. The complex global social arenas underlying broad societal issues cannot be studied in any deep way without considerations of economy and history, little of which we saw in the articles we analyzed. At the same time, broad concerns of economy and environment must include a concept of an individual or collective subject with their objectives and concerns. For example, (Pargman \& Raghavan, 2014) argue that sustainability in HCI should examine topics such as a steady state economy and the "limits to growth" investigated in economic models. Such analytical approaches are essential, but if they do not weave in human subjects with agency and agendas, they will never truly inform the discipline of human-computer interaction.

\section{Concluding remarks}

In this paper we analyzed how theory, and in particular activity theory, has worked out for HCI researchers. We found frequent and positive uses, and adaptation and development of activity theory in HCI. Our qualitative meta-synthesis indicated five specific purposes for which by HCI researchers use and make activity theory. HCI has produced activity theory classics that might approximate the classics of HCI information processing theory. We have discussed how our findings for activity theory may also be valid for other HCI theories. 
We expect that the diversity of issues and interests in our field will continue to produce the blooming, buzzing confusion that is HCI, while at the same time, its theories will ensure grounding for continued development, much as information processing theory allowed for the emergence of HCI as a recognized field. HCI theory is accumulating, whether we like it or not.

Concrete future research to follow up on this study would include interviewing HCI researchers from each category of our theory-makers. From a quantitative point of view, it would be interesting to test the initial characterization of five roles of theory and theory makers in HCI more formally and systematically by developing a codebook and by using independent raters from various HCI communities in the world. This could also be done for other theories than activity theory.

Finally, the current study could be taken forward by studying the use of activity theory in related fields such as information systems, which has recently shown an increased interest in activity theory. (Chatterjee, 2015), discussing design based research, proposes that activity theory may be used to bridge between researchers from different fields, especially social science and computer science, in a holistic manner in order to create design-based theories. We look forward to such cross-disciplinary efforts to strengthen our understanding of information technology and its impact on individuals and society.

\section{$7 \quad$ References}

1. Bargas-Avila, J. A., and Hornbæk, K. 2011. Old wine in new bottles or novel challenges: a critical analysis of empirical studies of user experience. Proceedings of the SIGCHI Conference on Human Factors in Computing Systems, CHI '11, 2689-2698, ACM.

2. Barr, P., Noble, J., and Biddle, R. 2007. Video game values: Humancomputer interaction and games. Interacting with Computers, 19 (2): 180-195.

3. Bartneck, C., and Hu, J. 2009. Scientometric analysis of the CHI proceedings. Proceedings of the SIGCHI Conference on Human Factors in Computing Systems, CHI' 09, 699-708, ACM. 
4. Benyon, D., and Imaz, M. 1999. Metaphors and models: conceptual foundations of representations in interactive systems development. Human-Computer Interaction, 14 (1): 159-189.

5. Blackwell, A. F. 2015. HCI as an Inter-Discipline. Proceedings of the 33rd Annual ACM Conference Extended Abstracts on Human Factors in Computing Systems, CHI '15, 503-516, ACM.

6. Bødker, S. 1989. A human activity approach to user interfaces. Human-Computer Interaction, 4 (3): 171-195.

7. Bødker, S. 1991. Through the Interface: A Human Activity Approach to User Interface Design. New Jersey: Lawrence Erlbaum Associates Inc.

8. Bødker, S. 2006. When second wave HCI meets third wave challenges. Proceedings of the 4th Nordic conference on Human-computer interaction: changing roles, NordiCHI '06, 1-8, ACM.

9. Bødker, S., and Andersen, P. B. 2005. Complex mediation. HumanComputer Interaction, 20 (4): 353-402.

10. Cajander, A., Janols, R., and Eriksson, E. 2014. On the establishment of user-centred perspectives. Proceedings of the 8th Nordic Conference on Human-Computer Interaction: Fun, Fast, Foundational, NordiCHI '14, 103-112, ACM.

11. Card, S., Moran, T. P., and Newell, A. 1983. The Psychology of Human-Computer Interaction: Hillsdale, NJ: LEA.

12. Carroll, J. M. 1991. Designing interaction: Psychology at the humancomputer interface (Vol. 4): CUP Archive.

13. Carroll, J. M. 2003. HCI models, theories, and frameworks: Toward a multidisciplinary science: Morgan Kaufmann.

14. Carroll, J. M., and Campbell, R. L. 1986. Softening up Hard Science: reply to Newell and Card. Human Computer Interaction, 2 (3): 227-249.

15. Chatterjee, S. 2015. Writing My next Design Science Research Master-piece: But How Do I Make a Theoretical Contribution to DSR? Proceedings of 23rd ECIS conference, Munster Germany, ECIS2015 Completed Research Papers: Paper 28.

16. Clemmensen, T. 2003, September 1-5, 2003. Usability Professionals' Personal Interest in Basic HCI theory. Proceedings of the ninth IFIP TC13 International Conference on Human -Computer Interaction, INTERACT '03, 639-646, IOS Press. 
17. Clemmensen, T. 2006. Whatever happened to the Psychology of Human-Computer Interaction? a biography of the life of a psychological framework within a HCI journal. Information Technology and People, 19 (2): 121-151.

18. Cole, M. 1996. Cultural Psychology: A Once and Future Discipline: A Belknap Press of Harvard University Press.

19. Cole, M., and Werstch, J. V. 1986. Preliminary remarks on the Soviet socio-cultural approach to mind and psychological research in the United States. Paper presented at the First International Congress on the Theory of Activity, Berlin October 1998.

20. Dourish, P. 2001. Where the action is: The foundation of embodied interaction: Massachusetts Institute of Technology.

21. Engeström, Y. 1987. Learning by expanding: Cambridge University Press.

22. Engeström, Y. 1999. Activity theory and individual and social transformation. In Y. Engeström, R. Miettinen and R. Punamaki Eds.), Perspectives on Activity Theory, 19-38. Cambridge University Press.

23. Fallman, D. 2011. The new good: exploring the potential of philosophy of technology to contribute to human-computer interaction. Proceedings of the SIGCHI Conference on Human Factors in Computing Systems, CHI '11, 1051-1060, ACM.

24. Greenwald, A. G., Pratkanis, A. R., Leippe, M. R., and Baumgardner, M. H. 1986. Under what conditions does theory obstruct research progress? Psychological Review, 93 (2): 216-229.

25. Gregor, S. 2006. The nature of theory in information systems. MIS Quarterly, 30 (3): 611-642.

26. Halskov, K., and Hansen, N. B. 2015. The diversity of participatory design research practice at PDC 2002-2012. International Journal of Human-Computer Studies, 74: 81-92.

27. Kaptelinin, V., and Nardi, B. 2012. Affordances in HCI: Toward a mediated action perspective. Proceedings of the SIGCHI Conference on Human Factors in Computing Systems, CHI '12: 967-976, ACM.

28. Kaptelinin, V., Nardi, B., Bødker, S., Carroll, J., Hollan, J., Hutchins, E., and Winograd, T. 2003. Post-cognitivist HCI: second-wave theories. CHI '03 extended abstracts on Human factors in computing systems, CHI '03: 692-693, ACM. 
29. Kaptelinin, V., and Nardi, B. A. 2006. Acting with technology: Activity theory and interaction design: Mit Press.

30. King, N. 2012. Doing template analysis. in Symon, Gillian, and Catherine Cassell, eds. Qualitative organizational research: core methods and current challenges. Sage, 426-450.

31. Kjærgaard, A., and Vendelø, M. T. 2015. The role of theory adaptation in the making of a reference discipline. Information and Organization, 25 (3): 137-149.

32. Kostakos, V. 2015. The big hole in HCI research. interactions, 22 (2): 48-51.

33. Kozulin, A. 1984. Psychology in Utopia: Toward a Social History of Soviet Psychology. Cambridge, Mass.: MIT Press.

34. Kuutti, K. 2010. Where are the Ionians of user experience research? Proceedings of the 6th Nordic Conference on HumanComputer Interaction: Extending Boundaries, NordiCHI '10, 715-718, ACM.

35. Kuutti, K., and Bannon, L. J. 2014. The turn to practice in HCI: Towards a research agenda. Proceedings of the 32nd annual ACM conference on Human factors in computing systems, CHI '14: 3543-3552, ACM.

36. Leontiev Leontyev), A. N. 1978. Activity, Consciousness, and Personality, (Vol. 44): Prentice-Hall Englewood Cliffs, $\mathrm{Nj}$.

37. Leontiev Leontyev), A. N. 1981. Problems of the development of the mind. Moscow, Russia: Progress.

38. Liu, Y., Goncalves, J., Ferreira, D., Xiao, B., Hosio, S., and Kostakos, V. 2014. CHI 1994-2013: Mapping two decades of intellectual progress through co-word analysis. Proceedings of the 32nd annual ACM conference on Human factors in computing systems, CHI '14, 3553-3562, ACM.

39. Monk, A., and Gilbert, G. N. 1995. Perspectives on HCI: diverse approaches: Academic Pr.

40. Nardi, B. A. 1996. Context and consciousness: activity theory and human-computer interaction: Mit Press.

41. Newman, W. 1994. A preliminary analysis of the products of HCI research, using pro forma abstracts. Proceedings of the SIGCHI conference on Human factors in computing systems, CHI' 94, 278-284, ACM.

42. Pargman, D., and Raghavan, B. 2014. Rethinking sustainability in computing: from buzzword to non-negotiable limits. 
Proceedings of the 8th Nordic Conference on HumanComputer Interaction: Fun, Fast, Foundational, NordiCHI '14: 638-647, ACM.

43. Rogers, Y. 2004. New Theoretical Approaches for HCI. Annual review of information science and technology (ARIST), 38 (1): 87-143.

44. Rogers, Y. 2012. HCI theory: classical, modern, and contemporary. Synthesis Lectures on Human-Centered Informatics, 5 (2): 1129.

45. Rubinshtein, S. L. 1946. Foundations of General Psychology Second edition ed.. Moscow, Russia: Uchpedgiz in Russian).

46. Stewart, J., Baker, N. L., Chaney, S., Hashimov, E., Imafuji, E., McNely, B., and Romano, L. 2012. A qualitative metasynthesis of activity theory in SIGDOC proceedings 2001-2011. Proceedings of the 30th ACM international conference on Design of communication, SIGDOC '12, 341348, ACM.

47. Vygotsky, L. S. 1978. Mind in Society. The development of higher psychological processes. Cambridge MA: Harvard University Press.

48. Walstrom, K., and Leonard, L. 2000. Citation classics from the information systems literature. Information and Management, 38 (2): 59-72.

49. Wertsch, J. V. e. 1981. The Concept of Activity in Soviet Psychology: Armonk, NY: M. E. Sharpe.

50. Winograd, T., and Flores, F. 1986. Understanding computers and cognition: A new foundation for design: Intellect Books.

\section{Appendix - the 109 papers that engage activity theory}

1. Ang, C. S., Zaphiris, P., and Wilson, S. 2011. A case study analysis of a constructionist knowledge building community with activity theory. Behaviour \& information technology, 30 (5): 537-554.

2. Arestova, O., Babanin, L., and Voiskounsky, A. 1999. Psychological research of computer-mediated communication in Russia. Behaviour and Information Technology, 18 (2): 141-147. 
3. Bardram, J. 1998. Designing for the dynamics of cooperative work activities. Proceedings of the 1998 ACM conference on Computer supported cooperative work, CSCW'98, 89-98, ACM.

4. Bardram, J. E. 2000. Temporal coordination - on time and coordination of collaborative activities at a surgical department. Computer Supported Cooperative Work: CSCW: An International Journal, 9 (2): 157-187.

5. Bardram, J. E. 2009. Activity-based computing for medical work in hospitals. ACM Transactions on Computer-Human Interaction (TOCHI), 16 (2): 1-36.

6. Bardram, J., and Doryab, A. 2011. Activity analysis: Applying activity theory to analyze complex work in hospitals. Proceedings of the 2011 ACM conference on Computer supported cooperative work, $C S C W$ '11, 455-464, ACM.

7. Barr, P., Noble, J., and Biddle, R. 2007. Video game values: Humancomputer interaction and games. Interacting with Computers, 19 (2): 180-195.

8. Barthelmess, P., and Anderson, K. M. 2002. A view of software development environments based on activity theory. Computer Supported Cooperative Work: CSCW: An International Journal, 11 (1-2): 13-37.

9. Baumer, E. P. S., and Tomlinson, B. 2011. Comparing activity theory with distributed cognition for video analysis: Beyond "kicking the tires". Proceedings of the SIGCHI Conference on Human Factors in Computing Systems, CHI'11, 133-142, ACM.

10. Bedny, G. Z., Karwowski, W. and Sengupta, T. 2008. Application of systemic-structural theory of activity in the development of predictive models of user performance. International Journal of Human-Computer Interaction, 24 (3): 239-274.

11. Bedny, G. Z., Karwowski, W., and Bedny, I. S. 2012. Complexity evaluation of computer-based tasks. International Journal of Human-Computer Interaction, 28 (4): 236-257.

12. Bedny, G., and Karwowski, W. 2003. A systemic-structural activity approach to the design of human-computer interaction tasks. International Journal of Human-Computer Interaction, 16 (2): 235-260. 
13. Bedny, I. S., Karwowski, W., and Bedny, G. Z. 2010. A method of human reliability assessment based on systemic-structural activity theory. International Journal of Human-Computer Interaction, 26 (4): 377-402.

14. Belkadi, F., Bonjour, E., Camargo, M., Troussier, N., and Eynard, B. 2013. A situation model to support awareness in collaborative design. International Journal of Human-Computer Studies, 71 (1): 110-129.

15. Benbunan-Fich, R., Adler, R. F., and Mavlanova, T. 2011. Measuring multitasking behavior with activity-based metrics. ACM Transactions on Computer-Human Interaction (TOCHI), 18 (2): $1-22$.

16. Benyon, D. and Imaz, M. 1999. Metaphors and models: Conceptual foundations of representations in interactive systems development. Human-Computer Interaction, 14 (1): 159-189.

17. Bødker, S. and Petersen, A. B. 2007. Seeds of cross-media production. Computer Supported Cooperative Work: CSCW: An International Journal, 16, 5, 539-566.

18. Bødker, S. 1989. Human activity approach to user interfaces. HumanComputer Interaction 4 (3): 171-195.

19. Bødker, S. 1996. Creating Conditions for Participation: Conflicts and Resources in Systems Development. Human-Computer Interaction, 11(3): 215.

20. Bødker, S. 1998. Understanding Representation in Design. HumanComputer Interaction, 13 (2): 107 - 125.

21. Bødker, S., and Andersen, P. B. 2005. Complex mediation. HumanComputer Interaction, 20 (4): 353-402.

22. Bødker, S., and Klokmose, C. 2013. From Persona to Techsona. In P. Kotzé, G. Marsden, G. Lindgaard, J. Wesson and M. Winckler (Eds.), Human-Computer Interaction - INTERACT 2013, vol. 8120, 342-349, Springer Berlin Heidelberg.

23. Bødker, S., Klokmose, C.N. 2011. The Human-Artifact Model: An Activity Theoretical Approach to Artifact Ecologies. HumanComputer Interaction, 26 (4): 315-371.

24. Carmien, S., Depaula, R., Gorman, A. and Kintsch, A. 2004. Increasing workplace independence for people with cognitive disabilities by leveraging distributed cognition among caregivers and clients. Computer Supported Cooperative Work: CSCW: An International Journal, 13 (5-6): 443-470. 
25. Carroll, J.M. 1996. Becoming social: Expanding scenario-based approaches in HCI. Behaviour \& Information Technology, 15 (4): 266-275.

26. Carroll, J. M., Neale, D. C., Isenhour, P. L., Beth Rosson, M. and Scott Mccrickard, D. 2003. Notification and awareness: Synchronizing task-oriented collaborative activity. International Journal of Human Computer Studies, 58 (5): 605-632.

27. Carroll, J. M., Rosson, M. B., Convertino, G. and Ganoe, C. H. 2006. Awareness and teamwork in computer-supported collaborations. Interacting with Computers, 18 (1): 21-46.

28. Chaiklin, S. 2007. Modular or integrated?-an activity perspective for designing and evaluating computer-based systems. International Journal of Human-Computer Interaction, 22 (1-2): 173190.

29. Chan, S. H. 2009. The roles of user motivation to perform a task and decision support system (DSS) effectiveness and efficiency in DSS use. Computers in Human Behavior, 25 (1): 217-228.

30. Chauvin, C., Morel, G., and Tirilly, G. 2010. The use of information and communication technology in the sea fishing industry. $B e$ haviour \& Information Technology, 29 (4): 403-413.

31. Clases, C., and Wehner, T. 2002. Steps across the border - cooperation, knowledge production and systems design. Computer Supported Cooperative Work: CSCW: An International Journal, 11 (1-2): 39-54.

32. Collins, P., Shukla, S., and Redmiles, D. 2002. Activity theory and system design: A view from the trenches. Computer Supported Cooperative Work: CSCW: An International Journal, 11 (1-2): 55-80.

33. Convertino, G., Farooq, U., Rosson, M. B., Carroll, J. M., and Meyer, B. J. F. 2007. Supporting intergenerational groups in computer-supported cooperative work (CSCW. Behaviour \& Information Technology, 26 (4): 275-285.

34. Convertino, G., Mentis, H. M., Slavkovic, A., Rosson, M. B. and Carroll, J. M. 2011. Supporting common ground and awareness in emergency management planning: A design research project. ACM Transactions on Computer-Human Interaction (TOCHI), 18 (4): article 22.

35. Decortis, F., Noirfalise, S., and Saudelli, B. 2000. Activity theory, cognitive ergonomics and distributed cognition: Three views 
of a transport company. International Journal of Human Computer Studies, 53 (1): 5-33.

36. Decortis, F., Rizzo, A. and Saudelli, B. 2003. Mediating effects of active and distributed instruments on narrative activities. Interacting with Computers, 15 (6): 801-830.

37. Dennen, V. P. 2014. Becoming a blogger: Trajectories, norms, and activities in a community of practice. Computers in Human Behavior, 36: 350-358.

38. Döweling, S., Schmidt, B., and Göb, A. 2012. A model for the design of interactive systems based on activity theory. Proceedings of the 2012 ACM conference on Computer supported cooperative work, $C S C W$ '12, 539-548, ACM.

39. Engestrom, Y., Engestrom, R. and Saarelma, O. 1988. Computerized medical records, production pressure and compartmentalization in the work activity of health center physicians. Proceedings of the 1988 ACM conference on Computer supported cooperative work, CSCW '88, 65-84, ACM.

40. Engeström, Y. 1999. Expansive visibilization of work: An activitytheoretical perspective. Computer Supported Cooperative Work: CSCW: An International Journal, 8 (1-2): 63-93.

41. Erskine, L. E., Carter-Tod, D. R. N. and Burton, J. K. 1997. Dialogical techniques for the design of websites. International Journal of Human Computer Studies, 47 (1): 169-195.

42. Fjeld, M., Lauche, K., Bichsel, M., Voorhorst, F., Krueger, H., and Rauterberg, M. 2002. Physical and virtual tools: Activity theory applied to the design of groupware. Computer Supported Cooperative Work: CSCW: An International Journal, 11 (1-2): 153-180.

43. Folcher, V. 2003. Appropriating artifacts as instruments: When design-for-use meets design-in-use. Interacting with Computers, 15, 647-663.

44. Gobbin, R. 1998. The role of cultural fitness in user resistance to information technology tools. Interacting with Computers, 9(3), 275-285.

45. Greenberg, S. 2001. Context as a dynamic construct. Human-Computer Interaction, 6, 257-268. 
46. Halverson, C. A. 2002. Activity theory and distributed cognition: Or what does CSCW need to DO with theories? Computer Supported Cooperative Work: CSCW: An International Journal, 11(1-2), 243-267.

47. Hannan, M. 2011. Analysis of the collaborative activities in software development processes from the perspective of chronotopes. Computers in Human Behavior, 27 (1): 248-267.

48. Hautasaari, A. 2013. Could someone please translate this?: activity analysis of wikipedia article translation by non-experts. Proceedings of the 2013 ACM conference on Computer supported cooperative work, CSCW '13, 945-954, ACM.

49. Herrmann, T., Hoffmann, M., Kunau, G. and Loser, K. U. 2004. A modelling method for the development of groupware applications as socio-technical systems. Behaviour \& Information Technology, 23 (2): 119-135.

50. Honold, P. 2000. Culture and context: An empirical study for the development of a framework for the elicitation of cultural influence in product usage. International Journal of Human-Computer Interaction, 12 (3-4): 327-345.

51. Houben, S., Bardram, J. E., Vermeulen, J., Luyten, K. and Coninx, K. 2014. Activity-centric support for ad hoc knowledge work: a case study of co-activity manager. Proceedings of the SIGCHI Conference on Human Factors in Computing Systems, CHI '13, 2263-2272, ACM.

52. Jaferian, P., Hawkey, K., Sotirakopoulos, A., Velez-Rojas, M., and Beznosov, K. 2014. Heuristics for Evaluating IT Security Management Tools. Human-Computer Interaction, 29 (4): 311-350.

53. Kaptelinin, V. and Nardi, B. 2012. Affordances in HCI: Toward a mediated action perspective. Proceedings of the SIGCHI Conference on Human Factors in Computing Systems, CHI '12, 967-976, ACM.

54. Kaptelinin, V. 2003. UMEA: Translating interaction histories into project contexts. Proceedings of the SIGCHI Conference on Human Factors in Computing Systems, CHI '03, 353-360, ACM.

55. Kaptelinin, V. and Bannon, L. J. (2012. Interaction design beyond the product: Creating technology-enhanced activity spaces. Human-Computer Interaction, 27 (3): 277-309. 
56. Klokmose, C., and Bertelsen, O. 2013. The Mysterious Whiteboard. In P. Kotzé, G. Marsden, G. Lindgaard, J. Wesson and M. Winckler (Eds.), Human-Computer Interaction - INTERACT 2013, vol. 8118, 37-54, Springer Berlin Heidelberg.

57. Korpela, M., Mursu, A., and Soriyan, H. A. 2002. Information systems development as an activity. Computer Supported Cooperative Work: CSCW: An International Journal, 11 (1-2): 111128.

58. Korpelainen, E., and Kira, M. 2013. Systems approach for analysing problems in IT system adoption at work. Behaviour and Information Technology, 32 (3): 247-262.

59. Kuutti, K. and Arvonen, T. 1992. Identifying potential CSCW applications by means of activity theory concepts: a case example. Proceedings of the 1992 ACM conference on Computer supported cooperative work, CSCW' 92 , 233-240, ACM.

60. Kuutti, K. and Bannon, L. J. 1993. Searching for unity among diversity: exploring the "interface" concept. Proceedings of the INTERACT'93 and CHI'93 conference on human factors in computing systems, INTERCHI '93, 263-268, ACM.

61. Kuutti, K. and Bannon, L. J. 2014. The turn to practice in HCI: Towards a research agenda. Proceedings of the SIGCHI Conference on Human Factors in Computing Systems, CHI '14, 35433552, ACM.

62. Lauche, K. 2005. Collaboration among designers: Analysing an activity for system development. Computer Supported Cooperative Work: CSCW: An International Journal, 14 (3): 253-282.

63. Law, E. L. and Sun, X. 2012. Evaluating user experience of adaptive digital educational games with activity theory. International Journal of Human Computer Studies, 70 (7): 478-497.

64. Liaw, S., Huang, H., and Chen, G. 2007. An activity-theoretical approach to investigate learners' factors toward e-learning systems. Computers in Human Behavior, 23 (4): 1906-1920.

65. Lundvoll Nilsen, L. 2011. Collaboration and learning in medical teams by using video conference. Behaviour \& Information Technology, 30 (4): 507-515.

66. Luse, A., Mennecke, B. E., Triplett, J. L., Karstens, N., and Jacobson, D. 2011. A Design Methodology and Implementation for Cor- 
porate Network Security Visualization: A Modular-Based Approach. AIS Transactions on Human-Computer Interaction, 3 (2): 104-132.

67. Macaulay, C., Benyon, D., and Crerar, A. 2000. Ethnography, theory and systems design: From intuition to insight. International Journal of Human Computer Studies, 53 (1): 35-60.

68. Mahatody, T., Sagar, M. and Kolski, C. 2010. State of the art on the cognitive walkthrough method, its variants and evolutions. International Journal of Human-Computer Interaction, 26 (8): 741-785.

69. Matthews, T., Rattenbury, T., and Carter, S. 2007. Defining, designing and evaluating peripheral displays: An analysis using activity theory. Human-Computer Interaction, 22 (1-2): 221-261.

70. Mccarthy, J. C., Healey, P. G. T., Wright, P. C. and Harrison, M. D. 1997. Accountability of work activity in high-consequence work systems: Human error in context. International Journal of Human Computer Studies, 47 (6): 735-766.

71. Meira, L. and Peres, F. 2004. A dialogue-based approach for evaluating educational software. Interacting with Computers, 16 (4): 615-633.

72. Miettinen, R., and Hasu, M. 2002. Articulating user needs in collaborative design: Towards an activity-theoretical approach. Computer Supported Cooperative Work: CSCW: An International Journal, 11 (1-2): 129-151.

73. Mohamedally, D., and Zaphiris, P. 2009. Categorization Constructionist Assessment with Software-Based Affinity Diagramming. International Journal of Human-Computer Interaction, 25 (1): 22-48.

74. Mwanza, D. 2001. Where theory meets practice: A case for an Activity Theory based methodology to guide computer system design. In M. Hirose (Eds), Human-Computer Interaction INTERACT'01, Amsterdam, 342-349, IOS Press.

75. Mühlfelder, M. and Luczak, H. 2003. Cognitive Analysis of Process Knowledge Transfer in Computer Supported Cooperative Work. International Journal of Human-Computer Interaction, 16 (2): 325-344.

76. Nardi, B. A., Schwarz, H., Kuchinsky, A., Leichner, R., Whittaker, S., and Sclabassi, R. Turning away from talking heads: The use of video-as-data in neurosurgery. Proceedings of the 
INTERACT'93 and CHI'93 conference on human factors in computing systems, INTERCHI '93, 327-334, ACM.

77. Nardi, B. A., Schiano, D. J., and Gumbrecht, M. 2004. Blogging as social activity, or, would you let 900 million people read your diary? Proceedings of the 2004 ACM conference on Computer sup-ported cooperative work, CSCW '04, 222-231, ACM.

78. Nardi, B. A., Whittaker, S., and Schwarz, H. 2002. NetWORKers and their activity in intensional networks. Computer Supported Cooperative Work: CSCW: An International Journal, 11 (1-2): 205-242.

79. Nardi, B. 2005. Beyond bandwidth: Dimensions of connection in interpersonal communication. Computer Supported Cooperative Work: CSCW: An International Journal, 14 (2): 91-130.

80. Neale, D. C., Carroll, J. M. and Rosson, M. B. 2004. Evaluating computer-supported cooperative work: models and frameworks. Proceedings of the SIGCHI Conference on Human Factors in Computing Systems, CHI '04, 122-121, ACM.

81. Norris, B., Wong, B.L., and Rashid, D. "Wayfinding/navigation within a QTVR virtual environment: preliminary results." (1999).B., D. o. Rashid, et al. 1999. Wayfinding/navigation within a QTVR virtual environment: Preliminary results. In M. A. Sasse and C. Johnson (Eds) Human-Computer Interaction INTERACT'99: IFIP TC. 13 International Conference on Human-Computer Interaction, INTERACT'99, 1-8, IOS Press.

82. Norros, L. and Nuutinen, M. 2005. Performance-based usability evaluation of a safety information and alarm system. International Journal of Human Computer Studies, 63 (3): 328-361.

83. Norros, L., Liinasuo, M. and Hutton, R. 2011. Evaluating the potential of new technological tools for safety critical work. Interacting with Computers, 23 (4): 299-307.

84. Oviatt, S., Cohen, A., Miller, A., Hodge, K. and Mann, A. 2012. The impact of interface affordances on human ideation, problem solving, and inferential reasoning. ACM Transactions on Computer-Human Interaction (TOCHI), 19 (3): 22.

85. Owen, C. A. 2001. The role of organisational context in mediating workplace learning and performance. Computers in Human Behavior, 17 (5-6): 597-614. 
86. Pargman, T. C. and Wærn, Y. 2003. Appropriating the use of a Moo for collaborative learning. Interacting with Computers, 15 (6): 759-781.

87. Pargman, T. C. 2003. Collaborating with writing tools: An instrumental perspective on the problem of computer-supported collaborative activities. Interacting with Computers, 15 (6): 737757.

88. Park, S. Y. and Chen, Y. 2012. Adaptation as design: Learning from an EMR deployment study. Proceedings of the SIGCHI Conference on Human Factors in Computing Systems, CHI '12, 2097-2106, ACM.

89. Paulson, B., Cummings, D., and Hammond, T. 2011. Object interaction detection using hand posture cues in an office setting. International Journal of Human Computer Studies, 69 (1-2): 1929.

90. Peña-Ayala, A., Sossa, H. and Méndez, I. 2014. Activity theory as a framework for building adaptive e-learning systems: A case to provide empirical evidence. Computers in Human Behavior, 30: 131-145.

91. Petersen, M. G., Madsen, K. H., and Kjær, A. 2002. The usability of everyday technology: emerging and fading opportunities. ACM Transactions on Computer-Human Interaction (TOCHI), 9 (2): 74-105.

92. Quinones, P.-A. 2014. Cultivating practice and shepherding technology use: supporting appropriation among unanticipated users. Proceedings of the 2014 ACM conference on Computer supported cooperative work, CSCW'14, 305-318, ACM.

93. Rabardel, P., and Bourmaud, G. 2003. From computer to instrument system: A developmental perspective. Interacting with Computers, 15 (5): 665-691.

94. Raven, J. M. 2006. Functional organs and computer use within collaborative group projects. Computers in Human Behavior, 22 (6): 981-990.

95. Roda, C. and Thomas, J. 2006. Attention aware systems: Theories, applications, and research agenda. Computers in Human Behavior, 22 (4): 557-587. 
96. Sambasivan, N., Cutrell, E., Toyama, K. and Nardi, B. 2010. Intermediated technology use in developing communities. Proceedings of the SIGCHI Conference on Human Factors in Computing Systems, CHI '10, 2583-2592, ACM.

97. Schmidt, K. and Wagner, I. 2004. Ordering systems: Coordinative practices and artifacts in architectural design and planning. Computer Supported Cooperative Work: CSCW: An International Journal, 13 (5-6): 349-408.

98. Sjölie, D. 2012. Presence and general principles of brain function. Interacting with Computers, 24 (4): 193-202.

99. Spasser, M. A. 2002. Realist activity theory for digital library evaluation: Conceptual framework and case study. Computer Supported Cooperative Work: CSCW: An International Journal, 11 (1-2): 81-110.

100. Tomlinson, B., Blevis, E., Nardi, B., Patterson, D. J., Silberman, M. S. and Pan, Y. 2013. Collapse informatics and practice: Theory, method, and design. ACM Transactions on Computer-Human Interaction (TOCHI), 20 (4): article 24.

101. Tuikka, T. 2002. Remote concept design from an activity theory perspective. Proceedings of the 2002 ACM conference on Computer supported cooperative work, CSCW '02, 186-195, ACM.

102. Turner, P., and Turner, S. 2001. A web of contradictions. Interacting with Computers, 14 (1): 1-14.

103. Voida, S., Mynatt, E.D. 2009. It Feels Better Than Filing: Everyday Work Experiences in an Activity-Based Computing System. Proceedings of the SIGCHI Conference on Human Factors in Computing Systems, CHI '09, 259-268, ACM.

104. Westerberg, K. 1999. Collaborative networks among female middle managers in a hierarchical organization. Computer Supported Cooperative Work: CSCW: An International Journal, 8 (1-2): 95-114.

105. Wright, P., Dearden, A., and Fields, B. 2000. Function allocation: A perspective from studies of work practice. International Journal of Human Computer Studies, 52 (2): 335-355.

106. Yardi, S. and Bruckman, A. 2011. Social and technical challenges in parenting teens' social media use. Proceedings of the SIGCHI Conference on Human Factors in Computing Systems, CHI '11, 3237-3246, ACM. 
107. Young, K. 2008. Toward a model for the study of children's informal Internet use. Computers in Human Behavior, 24 (2): 173-184.

108. Zager, D. 2002. Collaboration as an activity coordinating with pseudo-collective objects. Computer Supported Cooperative Work: CSCW: An International Journal, 11 (1-2): 181-204.

109. Zitter, I., Kinkhorst, G., Simons, R. J. and Ten Cate, O. 2009. In search of common ground: A task conceptualization to facilitate the design of (e)learning environments with design patterns. Computers in Human Behavior, 25 (5): 999-1009. 